Palabra Clave (La Plata)

ISSN: 1853-9912

palabraclave@fahce.unlp.edu.ar

Universidad Nacional de La Plata

Argentina

\title{
Las metamorfosis de la Colección Tezontle. El primer catálogo literario del Fondo de Cultura Económica
}

\author{
Cervantes Becerril, Freja Ininna \\ Las metamorfosis de la Colección Tezontle. El primer catálogo literario del Fondo de Cultura Económica \\ Palabra Clave (La Plata), vol. 9, núm. 2, 2020 \\ Universidad Nacional de La Plata, Argentina \\ Disponible en: http://www.redalyc.org/articulo.oa?id=350562513013 \\ DOI: https://doi.org/10.24215/18539912e086
}

Esta obra está bajo una Licencia Creative Commons Atribución-NoComercial-Compartirlgual 4.0 Internacional. 
Dossier: Catálogos y colecciones editoriales en Latinoamérica: abordajes teóricos, históricos y materiales

\title{
Las metamorfosis de la Colección Tezontle. El primer catálogo literario del Fondo de Cultura Económica
}

\author{
The metamorphoses of the Tezontle collection. The first literary catalogue of the Fondo de Cultura Económica \\ Freja Ininna Cervantes Becerril \\ Universidad Autónoma Metropolitana-Iztapalapa, México \\ frejina@hotmail.com
DOI: https://doi.org/10.24215/18539912e086
Redalyc: http://www.redalyc.org/articulo.oa?
$\mathrm{id}=350562513013$ \\ Recepción: 05 Febrero 2020 \\ Aprobación: 15 Marzo 2020
}

\section{Resumen:}

En este ensayo se analiza la conformación del catálogo literario de la Colección Tezontle del Fondo de Cultura Económica. Para ello se estudia el origen de las publicaciones literarias en el desarrollo del proyecto fundador de la editorial, y se atienden las peculiaridades de la colección entre 1940 y 1965. En este periodo de la historia del Fondo, que corresponde a las dos primeras direcciones de Daniel Cosío Villegas y Arnaldo Orfila Reynal, se observa la aparición de las primeras ediciones literarias con el sello Ediciones Tezontle y Tezontle que hasta 1954 el Fondo distribuyó y comercializó "desinteresadamente". A partir del Catálogo general de 1955, la serie Tezontle aparece como una colección más de la empresa editora, sumando su catálogo al resto de las publicaciones. Esta transición de sello independiente a colección exigió una metodología propia para el estudio de su naturaleza pragmática, la cual se relaciona con las políticas culturales de los editores del Fondo y su práctica editorial.

Palabras Clave: Colección Tezontle, Publicación literaria, Catálogo literario, Fondo de Cultura Económica, México.

\section{Abstract:}

this essay analyzes the formation of the literary catalogue of the Tezontle Collection, published by the Fondo de Cultura Economica (FCE). It studies the origin of literary publications in the development of the FCE's original project, paying special attention to the collection's characteristics between 1940 and 1965. During this time of the FCE's history, directed by Daniel Cosio Villegas (1934-47) and Arnaldo Orfila Reynal (1948-65), the first titles appear under the labels Ediciones Tezontle and Tezontle. These were distributed and marketed "without any vested interest" by the FCE up until 1954. As of 1955, the Tezontle series appears listed in the FCE's General Catalogue as one of the collections of the press, and its catalogue of titles is added to the rest of the FCE's publications. This transition from being an independent label to being part of the FCE's collection requires a distinctive methodology to study its pragmatic features, which are related to the cultural policies of the editors of the FCE and its publishing practices.

KEYWORDs: Tezontle Collection, Literary publishing, Literary Catalogue, Fondo de Cultura Económica, México.

\section{INTRODUCCIÓN: EN EL PRINCIPIO EL CAOS}

La identidad de la colección Tezontle es múltiple. Sus perfiles varios aparecen y desaparecen según la coyuntura y la necesidad del momento, porque su capacidad de adaptación supera cualquier perfil definido, ya que la serie carece de un programa razonado a diferencia del resto de las colecciones programáticas del Fondo de Cultura Económica (FCE). De ahí que su catálogo presente curiosas adherencias a lo largo de la historia de la empresa editora y que se perciba como lo más cercano a un caos originario. No obstante, es en su expresión caótica y contingente donde se encuentra la clave de su pragmatismo, entendido como esa pulsión de la praxis editorial que le ha permitido sobrevivir estilos e intereses duraderos o efímeros, servir a funcionarios de todo tipo y clase, a gobiernos políticos y crisis económicas, para cumplir una larga vida de 80 años en 2020 (Cervantes Becerril, 2015).

Su naturaleza mutable la distingue del vasto catálogo del FCE con más de 110 colecciones, entre otras razones porque en ella ha cabido todo desde 1940, una totalidad abarcadora en la que se avienen los más diversos géneros discursivos, temas disciplinarios, formatos, fórmulas y tipos de edición, estilos, estéticas y 
tradiciones gráficas, materialidades y un largo etcétera al que se le fueron sumando nuevas ampliaciones y desprendiendo otras para volverse nuevas colecciones. No obstante, en la administración actual de la editorial, con Paco Ignacio Taibo II como director del FCE, la octogenaria colección Tezontle parece dormir el sueño de los justos, despojada de plan editor y con un futuro incierto. En este impasse resulta oportuno recordar la colección que introdujo por vez primera la publicación literaria en la editorial y valorar sus funciones como colección pragmática en un periodo específico de la historia del FCE: las dos primeras direcciones editoriales con Daniel Cosío Villegas y Arnaldo Orfila Reynal.

A lo largo de 25 años, de 1940 a 1965, Tezontle experimentó cambios significativos y representó un laboratorio para la práctica editorial, además de mutar de sello "independiente" a colección legítimamente incorporada al proyecto editorial. La coyuntura del origen del sello Tezontle está ligada al retorno del escritor y diplomático Alfonso Reyes y al exilio de los intelectuales españoles republicanos, e institucionalmente con el vínculo de la historia de El Colegio de México (Colmex) con la del FCE. Los entrecruces de los sujetos de la edición, los libros y las instituciones en la colección Tezontle manifiestan las dimensiones de la práctica editorial ejercida como política cultural.

Para inferir la trama de estos vínculos fue necesario, en primer lugar, distinguir el perfil literario del catálogo general de Tezontle en sus primeros 25 años; y en segundo lugar, ordenarlo en función de direcciones, géneros literarios, fórmulas editoriales, tradiciones literarias y bibliográficas y campos literarios (nacionales, regionales, continentales, etc.). Este catálogo literario de Tezontle se cotejó y revisó con los catálogos generales e históricos del FCE y Colmex; y a partir de esta lectura comparativa fue posible inferir las razones que dieron lugar al sello Tezontle en tiempos del director Cosío Villegas y su posterior incorporación institucional durante la dirección de Orfila Reynal. Además esta lectura fue necesaria para guiar la consulta documental de los expedientes del FCE. Cabe señalar que el periodo trazado para el estudio de la colección lo caracterizan las coyunturas políticas que definieron la apertura de Tezontle, con la llegada del exilio intelectual republicano, y la expulsión, no menos política, de Orfila Reynal del FCE, como preámbulo de la "guerra sucia” en América Latina y cuyo escenario mayor fue la Guerra Fría (Cervantes Becerril, 2019).

\section{Metodología}

En el Catálogo General de 1955 publicado por Orfila Reynal, Francisco Giner de los Ríos cuenta el origen del primer libro de Tezontle, escrito bajo su autoría: La rama viva, publicado en 1940. También en esa presentación oficial de Tezontle, Francisco Giner de los Ríos narra la leyenda, la metamorfosis que dio nombre a la creación de la serie: "En uno de sus escasos momentos líricos, Cosío Villegas propuso que se pusiera al libro como pie centzontle, por aquello de la poesía y del ruiseñor. Dictada por teléfono a la imprenta la palabra, las zetas españolas debieron ser tan sólidas que el pájaro se trasmutó en piedra” (Giner de los Ríos, 1955, p. 387). Así el “centzontle" se transformó en "tezontle”, una piedra volcánica de color rojo que es típica del Altiplano mexicano y que adorna las fachadas de los edificios coloniales de la Ciudad de México. Sin embargo, los primeros títulos de Tezontle aparecieron sin el pie del FCE, y configuró su catálogo con las voces poéticas del exilio español republicano entremezcladas con los cantos y escritos de poetas y prosistas mexicanos e hispanoamericanos que fueron incorporándose a lo largo de una década. Además de Giner de los Ríos, publicó León Felipe su libro El gran responsable. (Grito y salmo), y al año siguiente, en 1941, apareció Primavera en Eaton Hastings. Poema bucólico con intermedios de llanto, de Pedro Garfias, seguido de Recinto y otras imágenes, del poeta mexicano Carlos Pellicer. En contraste con los libros naranjas de Economía, las portadas de Tezontle llamaron la atención por la belleza tipográfica, sencillez y refinamiento de sus cubiertas que ilustraron José Moreno Villa, Antonio Rodríguez Luna, Ramón Gaya y Elvira Gascón entre otros artistas del exilio español.

Una leyenda más distingue los primeros 15 años del catálogo de Tezontle compuesto por ediciones de autor. Esta práctica realizada por los autores editores del FCE con decidida voluntad estética, se traduce en el 
caso de la colección en una estrategia política para velar la publicación institucional de los escritores del exilio español recién llegados y de algunos funcionarios mexicanos de la escena cultural. Para ello, hubo consenso en difundir sus publicaciones bajo la categoría de "edición de autor", lo que pretendía alejar cualquier sospecha, si se conviene en entender por edición de autor la publicación de un título patrocinada por su creador bajo un sello cualquiera, aunque de preferencia de una editorial legalmente constituida, cuyo perfil sea ad hoc para publicar la obra específica. El presupuesto de una edición de autor no representa, en principio, riesgo económico ni comercial para un editor que no la distribuye en el mercado; aunque sí puede significar un dilema "ético" respecto del perfil o los perfiles sino encuentra lugar en el catálogo, ya que desfigura la identidad editorial y su prestigio.

De esta forma, los primeros autores editores de Tezontle presentaron y difundieron sus "ediciones de autor", pero esta condición sucedió en el menor de los casos, y fue más bien una política editorial que se aplicó sobre todo a los autores hispanoamericanos que desde el extranjero y con sus propios recursos buscaron ser publicados y distribuidos por el FCE, como los herederos de Manuel González-Prada que compilaron varios de sus escritos en El tonel de Diógenes y Alfredo Pareja Díez-Canseco con su novela El muelle. Así, en una fase temprana del catálogo de la colección, éste se diferencia en su práctica y política editoriales, porque representa la serie de algunos escritores representativos que escriben sobre su exilio publicándose a sí mismos con los medios e insumos de las instituciones que los acogieron laboralmente en México. En cambio para los autores mexicanos la publicación en Tezontle sirvió para prestigiar su obra y consolidar o prefigurar una trayectoria literaria, como en el caso específico de Alfonso Reyes y Max Aub. En lo que fue la primera dirección del FCE con Cosío Villegas, que en 1949 publicó Extremos de América en la colección, aparecieron los títulos de Felipe, Giner de los Ríos, Pedro Garfias, Emilio Prados, Max Aub y Eugenio Ímaz; y de la parte mexicana conformó el catálogo en primer lugar Reyes, responsable del sello y director silente de Tezontle, y el poeta Carlos Pellicer.

Sin embargo, si se consideran las condiciones restringidas de los primeros autores exiliados de Tezontle, el concepto de edición de autor es relativo. Además, los recién llegados vivieron subordinación política y lidiaban con las tensiones que su presencia despertaba en el país de recepción, dada su inmediata inserción laboral en las nuevas instituciones educativas y culturales. Cuando el poeta y traductor Giner de los Ríos afirma que "las ediciones de Tezontle han sido patrocinadas indistintamente por El Colegio de México o por el Fondo de Cultura Económica" (Giner de los Ríos, 1955, p. 389) no hay duda de que el término de "edición de autor" significa en este caso edición subvencionada, ya que en términos de producción, las publicaciones fueron cubiertas en su totalidad o parcialmente con fondos públicos. Un escenario opuesto al que se afirma en la versión oficial de la historia de la casa, que sostiene que la "peculiaridad [de Tezontle] consistía en que esos volúmenes se hacían en el FCE pero no llevaban su pie de imprenta debido a que el autor o algún particular financiaba gran parte o la totalidad de la edición, la cual quedaba a disposición del autor o del FCE para su distribución y comercialización” (Díaz Arciniega, 1996, p. 93). O la versión más reciente que refrenda a medias la versión oficial "siempre ha sido un secreto a voces que la otra 'parte' [no pagada por el FCE o el Colmex] la pagaba el propio autor" (Garciadiego, 2016, p. 99). De ahí que la peculiaridad de las ediciones de Tezontle, especialmente en la primera dirección del FCE, no está en definir las ediciones de autor, sino en observarlas como publicaciones institucionales deliberadamente veladas.

Si los primeros títulos de la colección fueron subvencionados en parte o en todo, según el caso, entonces la aparición del sello "independiente" Tezontle representa una solución estratégica ante una coyuntura singular: debido a que en los inicios de la Casa de España se empezaba a publicar obras literarias, antecedentes materiales de Tezontle, muy pronto se interrumpieron cuando la Casa se convirtió en una institución académica para llamarse El Colegio de México. Las razones por las que el sello Tezontle se mantuvo en cierta marginalidad no se debieron a la "incultura” de Daniel Cosío Villegas o a su odio por la literatura, como llegó a afirmar en una entrevista Octavio Paz, sino que "se trató de un tema de orden editorial y de especialización académica" (Garciadiego, 2016, p. 101). 
Los títulos marginales de Tezontle, identificados en la práctica por su "cuidado editorial”, lograron parecer ediciones de autor porque el proceso de publicación de cada libro recaía en un autor editor empleado de la institución, que asumía las labores de revisión del texto hasta la promoción del libro, como actividad extemporánea a su trabajo editorial. Aunque parecían ser publicados por un sello independiente a las instituciones que los patrocinaban, los primeros libros de Tezontle surgieron de las instalaciones y prensas del FCE: obras literarias que se editaban y distribuían sin costo económico a sus autores.

Antonio Alatorre, colaborador del Departamento Técnico del FCE, al igual que el escritor Juan José Arreola, declaró en algún momento sobre la participación financiera entre instituciones hermanas para publicar obras literarias: "El pie editorial, 'Tezontle', se estampó en no pocos libros distribuidos por el Fondo de Cultura Económica, impresos en 'su' imprenta (la Gráfica Panamericana), pero costeados por El Colegio de México” (Alatorre, 1990, p. 24). También existen las correspondencias y los documentos sobre las relaciones y los acuerdos editoriales que ilustran las prácticas tempranas del sello, misivas personales $\mathrm{u}$ oficiales entre funcionarios (de Reyes con Cosío Villegas y Orfila Reynal), que seleccionaron y determinaron las publicaciones de Tezontle, disponibles en el Archivo Histórico del FCE y que comprueban los acuerdos para sufragar los costos de cada edición. En este sentido, Antonio Alatorre da testimonio sobre las sugerencias que hizo para publicar nuevos títulos en la colección: "En 1949 ya había aprobado don Alfonso el subsidio para dos libros que yo le propuse: Varia invención, de Arreola, y Fenomenología de lo poético, de Arturo Rivas Sainz que se publicaron con el mismo pie editorial [Tezontle] y el mismo elegante formato que el de Octavio Paz, el de Arreola en noviembre y el de Rivas dos meses después" (Alatorre, 1990, p. 24).

Las condiciones de privilegio que influyeron en la producción de Tezontle y en su imagen no institucional por más de una década, también se explican por las tensiones políticas y económicas expresadas en el panorama de la prensa mexicana, que desde 1936 se leían en los diarios Excélsior y El Nacional con motivo de la llegada del exilio republicano español (Matesanz, 2000). Asimismo, en la década siguiente se desencadenó un ataque puntual contra impresores y editores debido a la ausencia de una industria editorial que ofertase publicaciones literarias. La crítica de jóvenes escritores mexicanos al gremio editor reclamaba también la falta de participación cultural y de responsabilidad de las instituciones respecto de la nueva literatura nacional. Ese fue el caso del novelista José Revueltas y del poeta Efraín Huerta, quienes desde publicaciones periódicas como El popular manifestaron sus desacuerdos en los primeros años de los cuarenta (Revueltas, 2018). La desinteresada publicación literaria de Tezontle dirigida por Reyes y auspiciada por Cosío Villegas velaba en última instancia el subsidio de Colmex y el FCE para publicar obras literarias, hecho que no pasó inadvertido. A tres años de existir el sello, circulaban distribuidos por el FCE, cinco títulos de españoles exiliados y dos de escritores mexicanos, ecuación que el joven poeta Paz advirtió muy pronto para sus lectores de El hijo pródigo, a propósito de una reseña elogiosa e introductoria al primer libro de Max Aub, San Juan tragedia, publicado en 1943 con el pie de imprenta Tezontle:

\footnotetext{
Apenas conozco la obra anterior de Max Aub. Algunos poemas, una pieza de teatro publicada en Hora de España, algún artículo, algún ensayo... Pero me bastan para estimarlo como uno de los pocos, si no el único autor teatral valioso de la última generación española, dos obras: La vida conyugal (que aún no ha sido publicada) y San Juan [...]. Resulta inexplicable que la tragedia de Max Aub no haya sido llevada al escenario (no, claro está, por nuestras compañías profesionales, que antes han desdeñado las obras de nuestros mejores dramaturgos, sino por algunas de esas semipolíticas y semifilantrópicas "sociedades para la defensa de...”). La edición es excelente. Ojalá la editorial Tezontle, que ha publicado pocos libros tan buenos como éste, enriquezca sus títulos con las obras de algunos autores mexicanos inexplicablemente ausentes aún. (Paz, 1988, pp. 233, 236).
}

Desde 1938, Paz reseñó y comentó publicaciones de los escritores españoles del exilio. En ese mismo año apareció el artículo "León Felipe", que publicó el 17 de julio en el periódico El popular, fundado por Vicente Lombardo Toledano. Desde inicios de los años cuarenta, Paz colaboró en diversos proyectos editoriales con los escritores del exilio: son conocidas sus participaciones en antologías, revistas como Romance y Taller y en la intensa red crítica que contribuyó a establecer, además de colaborar con los autores republicanos en 
distintos impresos. No obstante, y a una década de la contienda nacionalista de 1932, el campo literario mexicano no parecía ceder en sus oposiciones y contradicciones ante la amenaza fascista. Mientras los jóvenes escritores denunciaban una crisis del sistema en todas sus dimensiones, como la cultural y particularmente la de la crítica literaria, las posiciones entre grupos se radicalizaban ideológicamente. El caso de Paz en Tezontle es emblemático, ya que en 1949 logró publicar Libertad bajo palabra, con el consentimiento de Reyes, un título que fue presentado y difundido como edición de autor, pero que cubrió en su totalidad Colmex, según consigna Reyes en un oficio dirigido a Joaquín Díez-Canedo (Reyes, 1950).

La primera colección del FCE que publicó obras literarias no respondió al gusto variopinto de un director responsable o de un solo editor. De hecho, careció de esa figura anómala guiada por el arte de publicar libros para compartir sus lecturas y edificar un catálogo a la manera de una exquisita biblioteca de editor (Calasso, 2014). Por el contrario, en la colección se advierte la coexistencia de diferentes gustos e intereses editoriales que derivaron en una estantería polimorfa, atenta a las voluntades de sus autores también editores de su obra, y quienes, no obstante, siempre dependieron de la autorización del presidente de Colmex, es decir, el mismo Reyes, para publicar.

\section{Resultados y discusión}

Detrás de las leyendas del pájaro trasmutado en piedra y de las ediciones de autor, se observa a través de la historia de la colección momentos cruciales de la política cultural y de la historia editorial en México a nivel internacional. El Catálogo histórico 1938-2000 de La Casa de España y Colmex consigna uno a uno los títulos de la colección, al igual que los diferentes catálogos generales e históricos del FCE. La aparición de Tezontle en los catálogos de ambas instituciones muestra que fue un sello compartido, de ahí que sea posible explicar los tránsitos familiares de los libros. Cuando la Casa mudó a Colegio, la publicación de obras literarias que había iniciado debió cambiar de morada al FCE y refugiarse bajo un sello independiente, pues se apartaba tanto del proyecto general del FCE que no contemplaba publicar literatura como del perfil académico de Colmex. Reyes consintió en la creación del sello y el director editorial, Cosío Villegas, fue cómplice de su maestro. Así fue que la literatura se introdujo en la editorial bajo el resguardo de Reyes, y al margen de los proyectos editoriales de Cosío Villegas en su creación de colecciones, en principio disciplinarias y posteriormente americanistas: Tierra firme y Biblioteca americana, planeada por Pedro Henríquez Ureña mientras colaboraba con Gonzalo Losada desde Buenos Aires.

Sin duda, en el Catálogo histórico 1938-2000 se encuentra el código genético de Tezontle. Y como primer indicio aparece el título inaugural de Colmex que también podría ser el de la colección: El payaso de las bofetadas y Elpescador de caña, de Felipe, publicado en 1938, que sorprendentemente lleva en su portada el pie de imprenta del FCE, pero que ni siquiera el catálogo histórico más reciente de la editorial asienta ( Catálogo histórico, 2014). En la entrada del título del Catálogo histórico de Colmex se lee la siguiente precisión: "Este poema se publicó antes de la creación de la Colección Tezontle, pero por sus características tipográficas es claro que forma parte de ella" ( Catálogo histórico, 2000, p. 23). Si se considera lo anterior, el libro de León Felipe representa el eslabón de la colección compartida entre instituciones. El catálogo de Tezontle reaparece en la historia de las publicaciones del Colmex hasta 1958, porque según el editor José María Espinasa, la colección "marcó un hito en la historia del libro mexicano y El Colegio estuvo ligado a ese privilegiado momento” ( Catálogo histórico, 2000, p. 12). Al fallecer Reyes en 1959, Tezontle fue desdibujándose del catálogo de Colmex, para reafirmarse como colección legítima del FCE.

Estos aires de familia entre los catálogos históricos de ambas instituciones dan cuenta de la relación intelectual entre escritores, editores y artistas de ambas orillas, afincados en la cultura escrita y la convivencia con los libros. Asimismo, hablan de la política editorial que prevaleció durante la gestión de Cosío Villegas y Reyes como presidente de Colmex, de publicar con la leyenda oficial de "ediciones de autor" a los autores españoles que fueron sus amistades intelectuales durante su estancia en España. Una política editorial que 
permitió la continuidad de la colección a través de diferentes fórmulas y que el segundo director del FCE, Orfila Reynal, convirtió en un auténtico laboratorio editorial para ensayar y prefigurar el lanzamiento de nuevos proyectos, formatos y colecciones, como la muy anhelada colección Letras mexicanas aparecida en 1952.

Durante los primeros 25 años de vida de la colección, el catálogo alcanzó un total de más de cien títulos publicados, casi el ciento por ciento fue literario, pese a la falta de un programa específico. Si en un comienzo Tezontle alojó a la poesía, muy pronto introdujo a su cuerpo el ensayo literario, histórico, filosófico y antropológico, además del cuento, la novela, la crónica, las memorias y la biografía; incluso el teatro encontró lugar en ese gran escenario de la colección.

En cuanto al relato, el cuento y la crónica, Arreola publicó Varia invención; José Durand, Ocaso de sirenas. Esplendor de manaties; Ignacio Helguera, El monstruo y otros cuentos; Pedro Salinas, El desnudo impecable y otras narraciones y Francisco Tario su Tapioca Inn mansión para fantasmas. En novela se distingue la primera edición en español de Angustia del brasileño Graciliano Ramos, cuya ilustración de portada es obra de José Narro Celorio y Una manera de morir, del guatemalteco Mario Monteforte Toledo, ediciones con las que Orfila Reynal ensayó la creación de una serie que se llamaría Letras Hispanoamericanas. También destaca la edición conmemorativa de Doña Bárbara, del venezolano Rómulo Gallegos, bellamente ilustrada por Alberto Beltrán y con prefacio del autor, publicada en 1954 durante el exilio del escritor y expresidente venezolano. En ensayo, además de El tonel de Diógenes de Manuel González-Prada y Extremos de América de Cosío Villegas, se advierten Topia y utopia de Ímaz; Confesiones profesionales de José Gaos; Regreso de tres mundos, un hombre de su generación de Mariano Picón-Salas, con portada de Josep María Giménez-Botey; El heroismo intelectual de José Antonio Portuondo; Ensayos sobre literatura latinoamericana de Arturo Torres-Rioseco; Sentido de la presencia de Ramón Xirau y La filosofía como compromiso de Leopoldo Zea.

Dos escritores amantes de la tipografía y editores de Tezontle se distinguen durante este primer periodo en el que la serie mutó de sello a colección, por su presencia en el catálogo con dos bibliotecas de autor: Reyes y Aub. El autor de Visión de Anábuac dio seguimiento a la colección las primeras dos décadas, enriqueciendo el catálogo con la publicación de veinte obras en total, que van de Los siete sobre Deva: sueño de una tarde de agosto publicada en 1942, a la publicación de Albores: crónica de Monterrey. Segundo libro de recuerdos en 1960. Esta última edición fue póstuma y representa una edición homenaje al autor que compuso tipográficamente su editor holandés A. M. M. Stols. A la primera obra de Reyes le siguieron otras, como Ancorajes, Homero en Cuernavaca, Memorias de cocina y bodega, ilustrada por Elvira Gascón; por lo que a lo largo de 18 años Tezontle fue el sello personal más asiduo de Reyes, el cual le rindió espacio material para su proyección literaria a su retorno en México, y en el que no dejaría de editar sus escritos paralelamente a la elaboración de sus Obras completas a partir de 1955.

Aub publicó San Juan Tragedia en Tezontle, a unos meses de su arribo a México en 1943. Editó sus primeras obras de exilio con este pie de imprenta, ahí aparecieron Campo abierto, Campo cerrado y Campo de sangre de su serie "El laberinto mágico", la edición completa de su Sala de espera y una de sus mejores obras de madurez, Jusep Torres Campalans de 1958, libro ilustrado por sí mismo y maquetado a manera de una parodia gráfica de los libros comerciales de arte del editor francés Albert Skira, y que en la actualidad resulta una de las más lúdicas e inteligentes muestras de la colección Tezontle. En un periodo de 15 años, Aub publicó un total de 15 obras, pero a la muerte de Reyes, en realidad su primer editor en México. Sus publicaciones desaparecieron del catálogo de la colección.

En Tezontle figuran obras de autores reconocidos y de enorme valor para un estudio historiográfico e histórico literario en México, como los ya señalados Libertad bajo palabra de Paz o Varia invención y Confabulario de Arreola entre otros, que ameritan ser estudiados. Sin embargo, los títulos publicados por Reyes y Aub representan, en todo caso, un valor predominante de la función editorial en términos cuantitativos y cualitativos, digno de observarse en una colección pragmática. Atender a las condiciones de producción de los títulos de uno y otro escritor en el catálogo, así como el significado y el valor de sus prácticas, 
contribuye al conocimiento de las trayectorias literarias de ambos autores como complementarias a su proceso de formación profesional. Las perspectivas, los motivos y los incentivos para editar y publicar sus obras en Tezontle fueron muy diferentes para Reyes y Aub. No obstante, edificaron sus bibliotecas de autor con su práctica editorial, a manera de subcolecciones o series, espacios simbólicos en los que ambos participaron de una tradición filotipográfica:

[...] usan, o esperan que sus impresores usen, los recursos de formas librarias para transmitir con la mayor claridad lo que ellos quieren significar. Incluso cuando escritores, escribas, iluminadores o ilustradores, impresores y editores, aceptan sin más regirse por las convenciones propias de su época, sin intento alguno de innovar o de distinguirse, hay ciertos códigos a partir de los cuales, si no somos indiferentes a ellos, podemos recuperar importantes significados que de otra manera podríamos perder o malinterpretar (McKenzie, 2005, p. 19).

Este gesto filotipográfico de las bibliotecas alfonsina y aubiana de la colección Tezontle revela un espacio privilegiado para la creación, a manera de un selecto taller editorial donde se ejercita el arte literario, cuya intención se hace evidente en cada uno de sus títulos. Asimismo, la práctica editorial de Reyes y Aub en el catálogo resignifica el pragmatismo de Tezontle en el curso de su materialidad. De ahí que las condiciones y las prefiguraciones editoriales de ambos autores perfilan sus bibliotecas en direcciones opuestas respecto al momento de su configuración: en Reyes, al final de una larga ausencia y en su retorno al país de origen para consolidar con el reconocimiento institucional su carrera de escritor e intelectual en el campo literario mexicano; y en Aub, en sus empeños por restaurar una trayectoria literaria en el inicio de su destierro en México, como exiliado republicano español.

Entre sí, Reyes y Aub fueron amigos y seres de libros; convirtieron a Tezontle en su sello personal y lo usaron para prestigiar y legitimar sus trayectorias literarias. En cualquier caso, es innegable que las obras fueron publicadas en condiciones de privilegio, si se considera el lugar y la forma como fueron proyectadas. En las bibliotecas alfonsina y aubiana de la colección, los autores depositaron su conocimiento por la labor editorial, sus filiaciones y tradiciones editoriales, su experiencia bibliográfica y fervor bibliófilo, sus estilos y prácticas formativas en su profesionalización como hombres de letras y tareas sustantivas en el refinamiento de su carrera de escritores.

El conocimiento editorial manifiesto en estas bibliotecas de autor de Tezontle, permite recrear las experiencias previas de ambos en sus actividades en España y México. En Madrid, Reyes tuvo que trabajar arduamente para diferentes sellos editoriales como Espasa-Calpe o Calleja, para diarios y revistas, como $E l$ Sol, con artículos y reseñas. Asimismo fue responsable de elaborar bibliografías en el Centro de Estudios Históricos y en ediciones por encargo, realizó traducciones, además de tareas de corrección, y redacción de prólogos, presentaciones, estudios introductorios, etc., sin olvidar sus trabajos de editor póstumo con la obra completa de Amado Nervo (Reyes, 1996). Posteriormente, las labores editoriales de Reyes se pueden seguir en París, Buenos Aires y Río de Janeiro. Por su parte, en la ciudad de Valencia, Aub se inició en estas tareas como editor de sí mismo por signo negativo ante el rechazo de editores como Ortega y Gasset, al revelar su intuición y amor por la edición con la publicación de sus libros Geografía de 1929 y Fábula verde en 1932, además de sus obras poéticas, Poemas cotidianos, de 1925 y A, de 1933. La otra residencia editorial de Aub fue la Ciudad de México, en la que también realizó traducciones, antologías, presentaciones, correcciones y muchas otras actividades, como la promoción y divulgación de la literatura de forma impresa y en el medio radiofónico desde la Universidad Nacional Autónoma de México.

Del conjunto de estilos y géneros literarios y editoriales de Tezontle, las bibliotecas alfonsina y aubiana se destacan por su trayectoria más pronunciada en el catálogo. En ellas la perseverancia, el gusto, la tradición y la innovación fueron pautas reconocibles para identificar las tareas de estos autores en la colección Tezontle, en la que sus títulos fueron signos distintivos del catálogo diverso en el que se inscribieron: "Al unísono con la rica producción de Alfonso Reyes en sus manifestaciones ensayísticas y de la inquietud creadora de Max Aub” (Orfila Reynal, 1955), como definió Orfila Reynal la presencia de ambos se aprecia en un contrapunto animoso que dio vida a la colección durante sus primeras dos décadas. 
Las obras de Reyes en Tezontle representan una biblioteca de autor que formó con las reediciones mexicanas de su obra dispersa y a la que sumó gran parte de sus títulos finales ensayando y aun dilatando, en cierta forma, sus Obras completas, como en la actualidad se las conoce. Ante la aspiración de una literatura consumada y un corpus uniforme, nada más opuesto que el arribo emergente de Aub a Tezontle, con la publicación de sus obras anteriores al exilio y durante su periplo en campos de concentración para salvarse del olvido. En la continuidad de sus obras en la colección, Aub alojó una buena parte de su literatura y, como en sus principios valencianos, resistió el rechazo y la indiferencia de forma creativa editando sus propios libros, ediciones que representan en la actualidad un desafío estético y conforman una original y auténtica biblioteca aubiana, previa a su colección de autor Obras incompletas aparecida en Joaquín Mortiz.

\section{Conclusiones: la condición mutable de Tezontle}

Por lo regular, el estudio literario de colecciones, series o subcolecciones, parte de la existencia de un catálogo razonado que funciona como guía para adentrarse e interpretar la progresión de un programa o proyecto determinado que, pese a las condiciones adversas del proceso editorial, se resuelve sin contradicciones aparentes en un fenómeno propio del desarrollo de la cultura escrita. No obstante, esta obsesión por el catálogo ordenado se percibe constantemente amenazado por un principio contradictorio que oscila entre el riesgo a la pérdida del patrimonio escrito, de ahí su voluntad por mantenerlo, y el miedo al exceso, al "temor propio de una sociedad completamente invadida por su patrimonio escrito y por la imposibilidad de que cada individuo maneje y domestique esta abundancia textual" (Chartier, 1999, p. 24). A esta aprensión responde la voluntad de clasificar, organizar, elegir y definir los usos, las formas y las prácticas de producir y divulgar el conocimiento.

En este sentido, el catálogo general de Tezontle tiene el aspecto de un inventario azaroso, cuyo perfil lo determinaron las circunstancias del momento: el retorno definitivo de Reyes, el exilio intelectual de los republicanos españoles, la proyección empresarial e internacional de la empresa editorial del FCE, la política cultural latinoamericana, la desarticulación comercial del libro hispanoamericano, entre otras coyunturas y condiciones. Por ello, lo que se observa en el catálogo no es el cumplimiento de ideas sustentadas en un programa con una producción consecuente, sino una compulsión por materializar esfuerzos y aspiraciones literarias. Las dificultades se presentan cuando se considera a Tezontle al margen de su pragmatismo y se le juzga por su ausencia de programa, a manera de una colección no colección en el ejemplo extremo de la "colección blanca" de Gallimard que contiene toda la producción editorial indefinida y cuyo uso extensivo alude al poder simbólico del grado cero: "el blanco oficia de signo por la ausencia de significante" (Genette, 2001, p. 24).

También ha imperado sobre Tezontle la imagen del "cajón de sastre". Esta idea implica un desorden, es decir, una colección que no solo carece de programa sino que su producción apunta hacia todas partes. Los investigadores, ante este horizonte, suelen oponer una resistencia a estudiar este tipo de colecciones, ya que no encuentran en ellas un valor o una importancia. Sin embargo, esta característica en apariencia caótica demanda observar a Tezontle en función de sus prácticas editoriales. De ahí que sea necesario verla en segmentos, de forma fragmentaria, sin aspirar a una totalidad unitaria, sino en la contingencia de su producción que resulta, en todo momento, estratégica. Los discursos que insisten en velar su política editorial hasta la actualidad, en contraste con el desarrollo de esta investigación, confirma la pertinencia de indagar las huellas de la práctica editorial institucional en esta colección, en la que participaban intelectuales y artistas cercanos al poder en la primera mitad e inicios de la segunda del siglo xx.

El ejemplo extremo de la práctica editorial que recuerda la "colección blanca" para definir el pragmatismo de Tezontle, alude a su producción editorial que transgrede los límites y la definición del resto de los fondos editoriales, o lo que es igual, a su falta de correspondencia con los perfiles de las colecciones programáticas, y finalmente a la necesidad de su uso estratégico para resolver las tensiones y las problemáticas que los editores 
del FCE han experimentado dentro y fuera de la editorial. La materialidad de la colección, manifiesta en múltiples formatos y tipos de publicación (ediciones de autor, conmemorativas y facsimilares, libros de arte, libros de artista, ediciones ilustradas, iconografías, ediciones gráficas, etc.), es el signo extremo más evidente de su práctica editorial, que comprende todos los modelos posibles de libros y representa el corpus literario que dio origen a Tezontle transgrediendo el plan fundador del FCE: "A cada libro, su traje y confección: formato, tipografía, papel, ilustraciones. Nada ortodoxo ni comercial. La literatura se avecindó de esta suerte en el catálogo del Fondo y fue quizá germen de ideas y colecciones, propias y ajenas, que nadie puede acotar las repercusiones" (Giner de los Ríos, 1964, p. 541).

La dificultad metodológica que implica el estudio de una colección pragmática, el caso de Tezontle, exige situarse en la contingencia e inestabilidad de los procesos, en los efectos de las coyunturas que los producen y en las condiciones que determinan la aparición de los libros, con el propósito de observar e interpretar las características que dan sentido a la circulación y la transmisión de las obras literarias en su materialidad. El estudio del amplio catálogo de la colección comenzó a dar luces cuando se pudieron segmentar ciertos conjuntos de obras, autores, géneros literarios y prácticas editoriales que se correspondían. De estos subconjuntos sobresalió la práctica sistemática de dos autores en específico, Reyes y Aub, que confirmaba el pragmatismo de la serie con su intervención en el catálogo.

Respecto del perfil de la colección, el seguimiento de la producción editorial a lo largo de las primeras dos direcciones de Cosío Villegas y Orfila Reynal muestra que, pese al pragmatismo éste fue predominantemente literario, es decir que, mientras su destino y conducción estuvo a cargo de Reyes, Tezontle fue una serie literaria que atendió noblemente los intereses de sus editores: un espacio simbólico y material de privilegio institucional que estratégicamente migró de sello independiente a colección editorial. La lectura del catálogo de Tezontle permite concluir que durante la primera gestión albergó la literatura del exilio español en una proporción considerable, en contraste con la segunda dirección, en la que Tezontle manifestó un perfil más equilibrado de literatura mexicana e hispanoamericana respecto de la española, que posteriormente también incluyó obras de escritores hispanomexicanos.

Desde las diferentes lecturas que se realicen del catálogo de la colección se pueden descubrir y estudiar las condiciones materiales, las prácticas editoriales y las redes intelectuales que dieron sentido y existencia a la publicación de sus títulos. Como todo catálogo, Tezontle da indicios para escudriñar su historia editorial y apreciar el arribo consecuente o desvío "incidental" de sus obras, por lo que es posible evocarlas e imaginarlas en los espacios simbólicos de sociabilidad intelectual y artística en los que tuvo lugar su producción, así como articular estos ámbitos con las condiciones, los procesos y las políticas que las posibilitaron o las impidieron, además de explicar sus usos.

Una vez puesta en marcha la colección Letras Mexicanas en 1952, la producción de Tezontle se redujo considerablemente y sirvió a sus editores para mitigar los riesgos con tirajes menores cada vez que se publicaba un título de suspicaz recepción y que no se asimilaba al perfil del resto de las colecciones, pero que se resolvía necesariamente a manera de prebenda o compromiso. Una práctica editorial que opera en "una esfera que no siempre está en la punta de la lengua del discurso editorial, pero sin la cual este discurso no sería explicable ni realizable" (Castañón, 2012, p. 62) A partir de la inclusión oficial de Tezontle en 1955, la colección estuvo para atender los intereses del director editorial y su administración en turno, lo cual se evidencia con la partida de Orfila Reynal en 1965.

Las direcciones posteriores a la salida de Orfila Reynal, designadas desde entonces por el presidente de la República en turno, le darían a la colección un perfil todavía más variopinto. Esta cada vez mayor utilidad de Tezontle, caracterizaría el aspecto y el contenido de sus libros en ediciones fuera de colección, libros únicos aglutinados en un catálogo desordenado. A toda editorial de larga data y prestigio le conviene, tarde o temprano, una "colección blanca", para ejercer la práctica editorial sin afectar los perfiles de sus colecciones y corresponder a las necesidades culturales y comerciales que marcan las políticas del momento. Las diversas prácticas editoriales de Tezontle descubren mundos paradójicos en los que la edición se puede leer "como 
un signo intencional habitado y regulado por algo distinto, de lo cual también es síntoma" (Bourdieu, 1995, p. 15). Una colección que en su conjunto sorprende por su capacidad combinatoria, por sus tradiciones artísticas e intereses diversos y porque en ella se reúnen los libros más distintivos del FCE.

\section{RefERENCIAS}

Alatorre, A. (1990). Un momento en la vida de Alfonso Reyes (y una poesía suya inédita). En V. Díaz Arciniega (comp.), Voces para un retrato. México: UAM-Azcapotzalco / FCE.

Bourdieu, P. (1995). Las reglas del arte. Génesis y estructura del campo literario. Barcelona: Anagrama.

Calasso, R. (2014). "Los libros únicos", La marca del editor. Barcelona: Anagrama.

Castañón, A. (2012), "La edición y el editor", Trópicos de Gutenberg. Escenas y mitos del editor. Madrid: Trama Editorial.

Catálogo general. (1955) México: FCE.

Catálogo histórico. (2014). México: FCE.

Cervantes Becerril, F. I. (2015). El pájaro trasmutado en piedra: 75 aniversario de Tezontle. En La Gaceta, No 533/534. México: FCE.

Cervantes Becerril, F. I. (2019). El pájaro trasmutado en piedra: la Colección Tezontle del Fondo de Cultura Económica. Tesis doctoral. Universidad Nacional Autónoma de México, México.

Chartier, R. (1999). Cultura escrita, literatura e historia. México: FCE.

Díaz Arciniega, V. (1996). Historia de la casa. Fondo de Cultura Económica (1934-1996), México: FCE.

Garciadiego, J. (2016). El Fondo, La Casa y la introducción del pensamiento moderno en México. México: FCE.

Genette, G. (2001). Umbrales. México: Siglo XXI.

Giner de los Ríos, F. (1955). Tezontle. En Catálogo general. México: FCE.

Giner de los Ríos, F. (1964). Catálogo general 1934-1964. México: FCE.

La Casa de España y El Colegio de México. (2000). Catálogo histórico 1938-2000. México: El Colegio de México.

Matesanz, J.A. (2000), Las raices del exilio. México ante la guerra civil española 1936-1939. México: El Colegio de México / Universidad Nacional Autónoma de México.

McKenzie, D.F. (2005). Bibliografía y sociología de los textos. Madrid: Akal.

Orfila Reynal, A. (1955). Tarea en marcha. En Catálogo general. México: FCE.

Paz, O. (1988). Primeras letras 1931-1943. México: Vuelta.

Revueltas, J. (2018). La marea de los días. México: Universidad Nacional Autónoma de México.

Reyes, A. (1950), "Expediente de Alfonso Reyes”, Acervo Histórico del FCE, Legajo 1, folio 112.

Reyes, A. (1996). Historia documental de mis libros (t. 26 en Obras completas). México: FCE.

\section{BY-NC-SA}

